\title{
Materia Medica
}

\section{A Death in Primary Care}

\author{
Benjamin D. Sommers, MD, PhD ${ }^{1,2}$ \\ ${ }^{1}$ Harvard School of Public Health, Boston, MA, USA; 'Brigham \& Women's Hospital / Brookside Community Health Center Division of General \\ Medicine and Primary Care, Boston, MA, USA.
}

J Gen Intern Med 26(4):456-7

DOI: $10.1007 / \mathrm{s} 11606-010-1553-0$

(c) Society of General Internal Medicine 2010

$\mathrm{S}$ uddenly, in the middle of a friend's baby shower, my beeper went off. Along with a call-back number, the following apparently cryptic text message from the hospital operator appeared: "Please call Janice- last name unclear (she was crying)."

My heart dropped. The message's hidden meaning stared me in the face.

Dialing the number, as I had many times during my residency, I braced myself for the worst. Janice was the daughter and primary caretaker for Mrs. Smith, an 81-year-old woman with numerous chronic medical problems who had become one of my most frequent - and favorite - patients. Most of Janice's pages were routine: prescription refill requests, concern about her mother's insulin dose, or reporting worsening leg edema. But this one was far from routine, and my initial fear was soon confirmed. Janice answered tearfully, with other family members sobbing in the background. "Dr. Sommers, Mom's gone. She's gone."

I had first met Mrs. Smith two years before, when she was admitted to our General Medicine team with a suspicion for acute coronary syndrome. When I went down to the emergency room, Janice was there next to her mother, and the two of them told me with 100\% confidence, "This isn't a heart attack. It's another stroke." After taking a history and examining her, I agreed, and the MRI confirmed Mrs. Smith's self-diagnosis. A few days later, getting ready to go home, Mrs. Smith told me she needed a new primary care doctor since hers had moved away. I eagerly accepted. As a resident training in primary care, I was always happy to build my panel of patients.

For the next two years, I saw Mrs. Smith every month or two, usually in my office, occasionally in the hospital during an admission. These "social visits" when she was in the hospital were among the highlights of my day. Usually, when taking care of hospitalized patients, residents are busy with paperwork and handling all the details, while the outpatient doctor makes a rare appearance and is greeted like an old friend. When Mrs. Smith was in the hospital, I got to be the one walking into the room and seeing a familiar face light up. "Dr. Sommers, what are you doing here?" she would say with a smile. We would make small talk, and I would update her on where things stood. And I'd leave feeling as if I really had visited an old friend.

Meanwhile, Janice's messages on my beeper arrived regularly, keeping me on my toes and her mother's medical

Published online November 6, 2010 problems under control. Speaking of those problems, there were many: diabetes, asthma, heart failure, high blood pressure, multiple strokes, mobility impairment from arthritis, and coronary artery disease, among others. I learned a great deal about medicine simply by trying to keep up with Mrs. Smith's complicated situation, with the help of the frequent consultations from several specialists she was seeing.

Mrs. Smith's visits were always ones I looked forward to in my once-weekly resident clinic, which isn't always the case when treating someone with as many health problems as she had. She was a quiet, no-nonsense woman, with strong feelings about anything we discussed. She was always elegantly dressed, always polite, and over time, occasionally willing to smile at some of my jokes. I enjoyed our visits for several reasons - her calm, confident demeanor; her willingness to hear my viewpoint and discuss them; and her and her daughter's unassuming but very caring relationship, which was evident in every encounter.

She often surprised me at these visits, as our priorities frequently did not match up, but we usually could come to a reasonable understanding. During one memorable encounter, a barely noticeable rash on her elbows was causing her great distress, but not because it was itchy or painful. She explained, "I can't be seen wearing short sleeves with this sort of thing on my arms. Maybe I should get some skin moved from my thighs to my elbows." I was able to dissuade her from pursuing a skin graft, and we chose topical therapy instead. We balanced our conversations, addressing both cosmetic concerns and symptoms that troubled her, as well as managing her heart failure, diabetes, and the rest of her chronic conditions. In short, we made time for both her concerns and mine.

There were bumps in the road, including one unfortunate incident in which a car literally drove through her front door, prompting nightmares and flashbacks. For three months, this traumatic experience became the focus of our visits. This proud, stoic woman would hold back tears as she told me, "I keep seeing that car coming through my wall, and the face of the driver who died." Far more important than her blood pressure and glucose control was her inability to sleep or relax in her own home. With some time, therapy, and medication, her symptoms of post-traumatic stress disorder improved, and we settled back into our former routine.

My mailbox was filled regularly with notices - from visiting nurses, elder daycare, Medicare - all for Mrs. Smith. Her various forms and faxes probably consumed $40 \%$ of my total paperwork in clinic. If I had not liked her so much, the administrative burden would have been exasperating.

At one visit a few months ago, Mrs. Smith announced, "It's time for me to leave Boston. I can't deal with this cold anymore. 
I'm moving to Florida." I carefully put together a packet of papers for whoever would become her new doctor, with some sadness to be losing one of my favorite patients. At what was supposed to be our last visit, we hugged and said goodbye. But her plans changed due to family circumstances, so she remained here, and selfishly I was happy to resume our usual routine of visits, faxes, and pages. Most recently, I had called a week before her death, regarding another batch of refills. Janice gave me the usual answer when I asked how her mother was doing. "Oh, Mom's fine. She's good. We'll see you soon."

"I'm so sorry, Janice," I said into the phone, huddling in a quiet corner of my friend's apartment to escape the buzz of the party conversation. "This is such a shock." Her mother, traveling out of town, had collapsed suddenly, but Janice could not get any more details from the hospital. She asked if I would call on her behalf.

Steadying my own emotions, I called the out-of-town hospital and identified myself as Mrs. Smith's primary care physician. The emergency room doctor said, "She was found pulseless by the paramedics and arrived here in cardiac arrest. We did forty-five minutes of CPR and defibrillations but couldn't save her."

Calling Janice back, I delivered the news, and then listened sadly to Janice give voice to her heartbreak. As she spoke, a recurrent thought echoed in my head. This is my first patient to die.

Of course, that was not literally true. As a third-year resident, I'd taken care of more than a dozen patients who died in the hospital. But Mrs. Smith was the first whom I considered truly my patient. This moment crystallized for me the difference between inpatient medicine and primary care. When hospitalized patients died, I experienced a variety of emotions - sadness, surprise, guilt, curiosity. What happened? Could I have prevented it? Did we miss something? How is the family? But, as I spoke with Janice and tried to offer her some measure of solace, there were two additional emotions I hadn't experienced in this context before. Nostalgia. And a deep sense of loss.
As with other patients' deaths in the hospital, Mrs. Smith's passing left me sympathizing with her family's pain, and second-guessing myself as a clinician. Could I have done anything different to prevent her death? Should I have evaluated her for a defibrillator? Had I been assertive enough in asking her about any new cardiac symptoms?

But I also found myself reminiscing about two years of visits with her - the initial encounter in the emergency room, smiles in the office and in the hospital, her preference for short sleeves, a hug before her near-departure for Florida. Two years of letters, faxes, and beeper messages. I have had other patients die before, but Mrs. Smith was the first whose death prompted me to spend the next day writing an entire essay filled with memories of her.

And I will miss seeing her. She had scheduled an appointment with me in two weeks, an appointment she won't be able to keep. It will leave a large gap in my clinic day, if only figuratively, before another patient fills it. But perhaps it will be a new patient. Perhaps it will be the start of another meaningful long-term relationship. And that is why I decided to go into primary care when I finished residency last month, because of the unique bond that primary care creates between the doctor, patient, and the patient's family. It is a relationship like no other in medicine.

Acknowledgments: The names of the patient and family members have been changed to preserve anonymity. I am grateful to her family for allowing me to share these memories. I would also like to thank Bobby Gottlieb and Jeff Sommers for helpful comments. The author has no conflicts of interest to report.

Corresponding Author: Benjamin D. Sommers, MD, PhD; Harvard School of Public Health / Brigham \& Women's Hospital, 677 Huntington Ave, Kresge Room 406, Boston, MA 02115, USA (e-mail: bsommers@hsph.harvard.edu). 